\title{
Campo científico y terreno epistemológico
}

\author{
Rigoberto Martínez Escárcega \\ Instituto de Pedagogía Crítica \\ rigomarti@gmail.com
}

\begin{abstract}
Resumen
En el presente escrito se aborda una discusión en torno a los principios epistemológicos y políticos que permiten delimitar el objeto de estudio de las nociones de campo y terreno. Se emplea el concepto de sobredeterminación, cuyo origen se ubica en la teoría psicoanalítica, para adentrarse en la complejidad del campo científico. Se trasgrede los linderos disciplinares entre la filosofía y la sociología de la ciencia con el propósito de superar las visiones deterministas sobre la actividad científica.
\end{abstract}

\section{Palabras clave}

Epistemología, política, poder, determinismo y sobredeterminación.

\section{Introducción}

Las nociones figurativas de campo y terreno no se refieren al mismo objeto de estudio. El campo se inscribe en el ámbito de la sociología de la ciencia, mientras que el terreno se encuentra dentro de los linderos de la filosofía de la ciencia. El campo enfatiza lo político y el terreno centra su mirada en el aspecto epistemológico de la actividad científica. Sin embargo, es difícil comprender el campo científico sin los posicionamientos epistemológicos y, es imposible estudiar el terreno epistemológico sin abordar las relaciones de poder que se configuran en torno a la legitimidad científica. El campo y el terreno más que nociones antitéticas son elementos complementarios de una misma problemática teórica.

\section{Terreno epistemológico}

El posicionamiento epistemológico se puede presentar como un obstáculo o como un potenciador en la construcción de un objeto científico. El posicionamiento epistemológico asumido por el investigador, permite ver determinados objetos y al mismo tiempo hace invisible otros. Un cambio de terreno hace posible que esos mismos objetos adquieran visibilidad. Así pues, la construcción de un objeto científico está directamente relacionada con el territorio ocupado.

El terreno epistemológico está delimitado por las premisas valorativas del investigador, por los supuestos teóricos asumidos de forma consciente, y por los supuestos ideológicos implicados de forma inconsciente. La implicación delimita la territorialización. "La implicación debe ser cuidadosamente distinguida del compromiso. En el compromiso me quedo aún en el nivel de una psicología voluntarista del sujeto, es decir, que es solamente la intencionalidad lo que se toma en cuenta. La implicación es algo que se padece" (Ardoino, 1997, p. 60). Los supuestos teóricos delimitados de forma consciente por el investigador para construir un objeto de estudio, se presentan como un compromiso, donde está presente la voluntad y el libre albedrío. La implicación, por el contrario, elimina la noesis del sujeto, su confianza de 
libertad en el pensamiento; la implicación no se elige, sino que es consustancial a la constitución del sujeto. La implicación es la carga valorativa inconsciente que constituye al sujeto como sujeto sujetado a condicionamientos históricos. La territorialización está sobredeterminada tanto por los supuestos valorativos que implican al sujeto de forma inconsciente, como por el posicionamiento teórico con el cual se compromete de forma consciente.

El cambio de terreno es lo que permite ver un objeto y trascender la observación del dato empírico. Desde un territorio empirista, la observación se convierte en un obstáculo epistemológico que impide ver el objeto científico. Al cambiar de territorio, en función de la mutación de problemática teórica, se supera la observación del dato empírico y emerge a la mirada el objeto científico. El cambio de terreno implica una ruptura epistemológica.

El término de desplazamiento al igual que el de implicación, son construidos en el ámbito de la clínica, de la teoría psicoanalítica. El desplazamiento hace referencia al cambio de valencia psíquica en las manifestaciones psicopatológicas de la vida cotidiana (los sueños, los chistes, los olvidos, los recuerdos, el trastabarse en el habla, el trastocar las cosas, etc.), como síntomas a partir de los cuales se expresan las pulsiones sexuales reprimidas de forma inconsciente. El desplazamiento al igual que la condensación y la figuración, son mecanismos de censura que emplea el aparato psíquico para darle acceso a la conciencia a los contenidos del inconsciente (Freud, 2006).

Cuando se habla de desplazamiento epistemológico, se parte del supuesto según el cual, el objeto científico, como objeto de pensamiento construido a partir del objeto pensado, cambia su valencia psíquica en los datos empíricos, a manera de censura. Desde un territorio empírico, los datos se presentan como una evidencia incontrovertible de la realidad, desconociendo que los datos empíricos no son el objeto real, el objeto pensado, sino una mediación ideológica del sujeto, una visión del mundo construida a partir de las implicaciones del sujeto. El desplazamiento epistemológico implica descubrir las perversiones del dato empírico, asumir que el dato empírico está gobernado por los supuestos valorativos inconscientes del sujeto. Para identificar el desplazamiento epistemológico en el objeto de pensamiento, es imprescindible mutar de problemática teórica, construir un nuevo sistema conceptual a partir del cual se pueda cuestionar al dato empírico. Y la mutación de una problemática teórica está condicionada a su vez, por un cambio de terreno. Cuando se identifica el desplazamiento epistemológico del objeto pensado en el objeto de pensamiento es posible generar una ruptura epistemológica, la base para la emergencia de un objeto científico.

Habría que señalar que existe una diferencia entre cambio de terreno y mutación de problemática. El terreno está delimitado tanto por los compromisos teóricos asumidos de forma consciente, como por las implicaciones axiológicas padecidas de forma inconsciente; pero son los mecanismos inconscientes los que gobiernan la demarcación territorial. Por el contrario, la problemática teórica está delimitada principalmente por compromisos teóricos asumidos de forma consciente, por un sistema de conceptos construidos de forma voluntaria. Sin embargo, a toda problemática teórica le subyace implicaciones axiológicas inconscientes, elementos ideológicos subjetivos, que propician que un objeto científico no se dé en su complitud, en su acabamiento, en el fin del desarrollo cognoscente, en el encuentro autorreferencial del conocimiento absoluto consigo mismo. El conocimiento científico se caracteriza por un afán insaciable de negación, revolución y autodestrucción. 
La territorialización es una valoración axiológica ante y sobre el objeto pensado, mientras que una problemática teórica es una conceptualización ante y sobre un objeto de pensamiento. Existe una mutua determinación entre territorio y problemática; el territorio epistemológico ocupado hace posible la mutación de una problemática teórica $\mathrm{y}$, la formulación de una nueva problemática teórica, lleva implícita un cambio de territorio. El cambio de territorio y la mutación de problemática teórica no pueden comprenderse como un simple cambio de perspectiva según el modelo explicativo de la psicología de la Gestalt (Khun, 1971); más bien se debe acudir a la noción de desplazamiento epistemológico tal como lo expone la teoría psicoanalítica, el enfoque clínico y la epistemología rupturista.

El terreno como objeto de estudio no es empíricamente observable, sólo un acercamiento clínico lo convierte en un objeto epistemológicamente visible, en tanto que está gobernado por lo inconsciente, por lo profundo, por las obsesiones psicopatológicas que constituyen al sujeto sujetado a su ilusión de libertad en el pensar. La clínica permite ver lo que no se observa, leer los silencios, identificar la palabra en la no palabra, descubrir la falta de palabra en la palabra, pesquisar los recuerdos en los olvidos y los olvidos en los recuerdos, vislumbrar las verdades de una mentira y las mentiras de una verdad.

La clínica trasciende la observación empírica construyendo una mirada acuciosa sobre un universo complejo que nos tiene atrapados con sus enigmas. La clínica tiene como objeto de estudio al inconsciente, lo que escapa a la voluntad de los sujetos.

A partir del posicionamiento epistemológico los agentes entablan una lucha en torno a la legitimación científica, dando forma al campo científico. Pero aquí entramos a los linderos de la sociología de la ciencia.

\section{Campo científico}

El campo científico se define como un espacio específico donde cobra forma una lucha entre los agentes que ocupan diferentes terrenos epistemológicos en torno a la imposición $\mathrm{y} / \mathrm{u}$ oposición a los criterios de legitimidad científica.

Es importante enfatizar que el campo en tanto sistema de relaciones objetivas, es un objeto de estudio empírico, es decir, que los agentes que conforman el campo dan forma a un sistema de relaciones que escapan a su conciencia. El campo se compone tanto por relaciones de subordinación, opresión y dominación, como por relaciones de contestación, oposición y resistencia. Es importante hacer una distinción conceptual entre subordinación, oposición y dominación. Ernesto Laclau y Chantal Mouffe sostienen:

Entenderemos por relación de subordinación aquélla en la que un agente está sometido a las decisiones de otro - un empleado respecto a un empleador, por ejemplo, en ciertas formas de organización familiar, la mujer respecto del hombre, etc. -. Llamamos, en cambio, relaciones de opresión a aquellas relaciones de subordinación que se han transformado en sedes de antagonismos. Finalmente, llamamos relaciones de dominación al conjunto de aquellas relaciones de subordinación que son consideradas como legítimas desde la perspectiva o juicio de un agente social externo a las mismas - y que puedan, por tanto, coincidir o no con las relaciones de opresión actualmente existentes en una formación social determinada (2004, p. 196).

La subordinación se presenta cuando una relación de imposición se naturaliza, cuando se asume la superioridad intelectual como natural, como dada por capacidades intelectuales distintas en función de las cuales se establece la división social del trabajo científico. La subordinación es la asunción acrítica de los principios epistemológicos de legitimidad científica. Una relación de 
subordinación no presenta conflictos políticos, en tanto que, los subordinados asumen como natural su dependencia hacia los subordinadores.

Una relación de opresión se presenta cuando se ha desnaturalizado la imposición de los principios epistemológicos de legitimidad científica, cuando la hegemonía en el campo se concibe como una posición política más que como una división social del trabajo científico basada en méritos intelectuales. La relación de opresión es conflictiva, contestataria, ya que se ha puesto en tela de juicio la legitimidad del ejercicio institucionalizado del poder. Las relaciones de opresión dentro de un campo se dan por la emergencia de nuevos principios de legitimidad científica, por la ocupación de nuevos terrenos epistemológicos a partir de los cuales se formulan problemáticas teóricas novedosas y se construyen objetos científicos originales. Entonces las posiciones que mantienen la hegemonía en el campo se presentan como un obstáculo epistemológico. La territorialidad y la lucha por la legitimidad científica, son el motor, el detonante para que las relaciones de subordinación se conviertan en relaciones de opresión.

Una relación de dominación se presenta cuando es utilizado el poder institucionalizado (control sobre las instituciones que producen conocimiento, control sobre los recursos con los que se produce investigación y control sobre los órganos de difusión del conocimiento) para imponer los criterios de legitimidad científica que defiende el grupo que mantiene la hegemonía en el campo. La dominación es un acto basado en la violencia simbólica a través del cual el poder amplía su territorialización epistemológica.

Existe una relación compleja entre subordinación, opresión y dominación. La dominación puede lograr relaciones de subordinación cuando se han naturalizado e interiorizado los principios de legitimidad científica dominante. Pero también se puede presentar una dominación como una relación de opresión, cuando el grupo dominante impone a una comunidad científica escéptica los criterios de legitimidad científica, utilizando los medios institucionalizados de control. A pesar de que los criterios de legitimidad científica estén en crisis, de que la ciencia oficial haya perdido su capacidad explicativa frente a un conocimiento científico emergente, la ciencia oficial puede seguir manteniendo la hegemonía en el campo durante un tiempo indefinido, gracias a su relación con el poder del estado.

Politizar lo epistemológico no implica asumir una visión economicista y determinista del campo, en donde se supedita el desarrollo del conocimiento científico a las condiciones económicas y sociales en las que está inmerso. Si bien se reconoce un papel importante a las condiciones históricas en el desarrollo de la ciencia, el campo científico está sobredeterminado por múltiples factores que en interacción dialéctica, hacen que emerja una autonomía relativa. La autonomía tiene un sentido dialógico, sistémico y hologramático - fractal.

La autonomía le permite al campo ser una autoorganización con una dinámica propia, con carácter único e irrepetible. El campo es un todo complejo autorregulado. Edgar Morín señala que: "[E]s preciso un pensamiento complejo en el que la autonomía no aparezca como fundamento, sino como emergencia organizacional que retroactúa sobre las condiciones y procesos que la han hecho emerger" (2006, p. 126). La autonomía es dialógica porque se basa en el conflicto, la lucha y la contradicción; es sistémica, ya que el campo visto como totalidad es más que la suma de las partes; es holístico porque sin las partes es imposible comprender el todo y viceversa; es hologramático - fractal, ya que la parte contiene al todo, y el todo explica el comportamiento de las partes.

La autonomía no es igual a independencia, ya que si bien la autonomía 
dota al campo de un carácter organizacional único, la dinámica propia del campo se configura en relación con los elementos históricos, económicos, políticos y sociales de su contexto. Por el contrario, la independencia hace referencia a un fenómeno de disyunción, aislamiento y parcelación. La autonomía se inscribe en una visión ecológica compleja, donde la totalidad está compuesta por partes, formando parte a su vez de una totalidad más amplia. La independencia es atomista, trata de desvincular a las partes de la totalidad. Por tanto, el campo es autónomo pero no es independiente.

Si bien el campo es dialógico, es decir, que está gobernado por la lucha, el conflicto y la confrontación entre las diversas posiciones epistemológicas entorno a la imposición de los criterios de legitimación científica, habría que diferenciar entre prácticas de oposición y prácticas de resistencia. Cuando un terreno epistemológico hegemónico es cuestionado por la emergencia de una nueva territorialización, las relaciones de subordinación se convierten en relaciones de opresión, dando origen a la lucha y al enfrentamiento. Una relación de oposición se presenta cuando los agentes luchan por los privilegios del campo, sin cuestionar los principios de legitimación científica del terreno que se ocupa. Una lucha de oposición no cuestiona el orden establecido en el campo, sino a los agentes que detentan el poder. Una relación de oposición quiere cambiar a los agentes, pero no a los principios epistemológicos que defienden. Una lucha de oposición, aunque cuestiona a los agentes que detentan el poder en el campo, puede resultar profundamente retardataria y conservadora. "En la medida en que las conductas de oposición supriman las contradicciones sociales y simultáneamente se fusionen - más que desafíen - la lógica de la dominación ideología, no caerán en la categoría de la resistencia sino de su opuesto, esto es en la acomodación y el conformismo" (Giroux,
2003, p. 146).

Las luchas de resistencia cobran forma cuando un nuevo posicionamiento epistemológico cuestiona los principios de legitimidad científica dominantes. La lucha de resistencia quiere revolucionar el campo, el saber, los principios lógicos en los que se basa la ciencia oficial. La resistencia es una lucha radical contra el terreno epistemológico dominante. "El valor del constructo de resistencia reside en su función crítica, en su potencial para expresar las posibilidades radicales contenidas en su propia lógica y los intereses contenidos en el objeto de su expresión" (Giroux, 2003, p. 146). Las luchas de resistencia en el campo científico están inspiradas en un afán imperioso por dar forma a nuevos regímenes de verdad.

Las luchas en el campo científico no sólo se presentan entre los diferentes posicionamientos epistemológicos, en su interés por imponer los criterios de legitimidad científica, sino que al interior de cada terreno también se presentan luchas por acceder a los privilegios del poder.

\section{Conclusiones}

El campo científico es un espacio territorializado, un entramado de relaciones de poder en disputa, donde los diferentes posicionamientos epistemológicos luchan por imponer los criterios de legitimidad científica, y donde los agentes se enfrentan por acceder y monopolizar los privilegios del poder. La dominación y la contestación son elementos constitutivos de la dinámica de un campo científico. Lo epistemológico y lo político se fusionan dando forma a una totalidad compleja y concatenada. Las nociones de campo y de terreno son complementarias más que divergentes; la dinámica de un campo no se puede comprender sin la territorialización epistemológica, y la territorialización epistemológica sólo cobra sentido heurístico a la luz de la politización del campo científico. La relación entre campo y terreno, es la misma 
que se establece entre la filosofía y la sociología de la ciencia. A la sociología de la ciencia le interesa la parte política del quehacer científico, mientras que a la filosofía de la ciencia le interesa los fundamentos teóricos a partir de los cuales se demarcan los criterios de legitimidad científica.

Es importante señalar que no sólo lo epistemológico y lo político caracterizan al campo científico, sino que su dinámica está sobredeterminada por lo económico, lo político y lo ideológico. Por lo que el campo científico se puede definir como una configuración de relaciones de poder territorializadas epistemológicamente $\mathrm{y}$ sobredeterminadas históricamente.

\section{Referencias}

Ardoino, Jacques (1997), La formación de investigadores en educación, trad. Patricia Ducoing Waty, Conferencia Magistral pronunciada en el IV Congreso Nacional de Investigación Educativa, organizado por el Consejo Mexicano de Investigación Educativa.

Ardoino, Jacques (2005), Complejidad y formación. Pensar la educación desde una mirada epistemológica, Nilda Venticinque y Sergio Schwartzman, Coedición Universidad Nacional de Buenos Aires y Ediciones Novedades Educativas, Buenos Aires, Argentina.

Bourdieu, Pierre (2008), Los usos sociales de la ciencia, trad. Horacio Pons y Freud, Sigmund (2006), A propósito de las críticas a la neurosis de angustia, vol. 3, en "Obras completas", trad. José Luis Etcheverry, Amorrortu Editores, Argentina, 24 vols.

Giroux, Henry (2003), Teoría y resistencia en educación, trad. Ada Teresita Méndez, Siglo Veintiuno Editores, México.

Khun, S. Thomas (1971), La estructura de las revoluciones científicas, trad. Agustín Contin, Fondo de Cultura Económica, México.

Laclau, Ernesto y Chantal Mouffe (2004), Hegemonía y estrategia socialista. Hacia una radicalización de la democracia, Fondo de Cultura Económica, Argentina.

Morin, Edgar (2006), El método 2. La vida de la vida, trad. Ana Sánchez, Ediciones Cátedra, España. 